\title{
Promotion and Application of Innovative Technology in the Construction of Yunmao Expressway Green Road
}

\author{
Fuqing Han ${ }^{1}$, Zengqi $\mathrm{Ma}^{2}$, Weili Wang ${ }^{3}$, Guoguo $\mathrm{He}^{4 *}$ and Shegang Shao \\ 1,2,3,4 Yun Mao Expressway, Guangzhou, Guangdong Province, 510623, China \\ ${ }^{5}$ Research Institute of Highway Ministry of Transport, Beijing, 100086, China
}

\begin{abstract}
With Yunfu Luoding city to Maoming Xinyi city highway as the support, builders focus on introducing innovative technology in the process of creating green road demonstration project, promoting energy conservation and emission reduction, reducing common quality problems, improving the technical level and management level of green road construction, and playing a reference role for the scientific application of innovative technology in common national and provincial highways.
\end{abstract}

\section{Introduction}

Science and technology are the primary productive forces, and scientific and technological innovation is an important strategic support for improving social productivity. The concept of green highways often needs to be implemented through advanced technologies and methods[1]. The implementation of innovation drive not only depends on the breakthrough and improvement of key technologies, but also depends on advanced technology and successful experience to actively promote it on a larger scale. That is to say, while carrying out technological innovation, the green highway must also carry out conceptual innovation and mechanism innovation. While seeking new methods and means to solve existing problems, it is also necessary to apply existing technologies and measures to a wider field to achieve the desired effect. With the rapid development of highway engineering construction, the "four new" technologies of new technologies, new processes, new materials and new equipment are constantly being favored and applied in highway engineering design, construction and maintenance, which not only improves the quality of highway engineering construction. The scientific and technological content has also greatly improved the quality of highway engineering construction[2].

In 2016, the Ministry of Transport issued "Guiding Opinions on the Implementation of Green Highway Construction" in order to implement green transportation. The document states that it is necessary to implement innovation drive, achieve scientific efficiency, and strengthen research on green highway technology. We will vigorously carry out research and development on key technologies for green roads, and accelerate research on new technologies such as road ecological protection and restoration, and the construction of road carbon sinks. We will vigorously promote the informatization of construction management. Based on the concept of "Internet plus", we will accelerate the application of modern information technologies such as cloud computing and big data, and effectively improve the level of construction management intelligence.

In recent years, the Highway Department of Guangdong Province has been vigorously promoting and applying innovative technologies to the ordinary national and provincial highways. In order to systematically summarize the achievements and experience of highway "four new" technologies over the years, constantly improve the level of highway maintenance technology, and better meet the needs of economic and social development and people's travel, this paper discusses the status quo of the application of innovative technologies in Yunmao expressway.

\section{Project Overview}

The Yunmao Expressway is the link between the "Nine Longitudinal Lines" of Luoyang Expressway and the "10 Longitudinal Lines" of Baomao National Expressway planned by the Guangdong Expressway Network. The Bay Expressway is an important economic trunk line from the western Guangdong mountainous region and the northern part of Beibu Gulf to the Pearl River Delta. The total length of the route is $129.816 \mathrm{~km}$, from east to west passing Luoding, Xinyi and Gaozhou. Because Yunmao Expressway is located in a mountainous and heavy hilly area, the terrain is undulating, there are many long uphill and long downhill sections, many high slopes, high pier bridges, high bridge-tunnel ratio, high liquid limit soil, soft soil, etc Dense rock, soil, collapse, karst and other bad geology are more common, so Yunmao Expressway is a typical mountain highway.

The Yunmao Expressway faces the following difficulties in the construction process: the terrain and geomorphology and engineering geological conditions

"Corresponding author's e-mail: 646461088@qq.com 
are complex, and the safety risk of local sections is prominent; there are many ecologically sensitive areas along the project, and the ecological and environmental protection requirements for highway construction are extremely high; Operational security is difficult, and energy conservation and environmental protection requirements are high. According to the above difficulties, carry out targeted innovation work, build a "four new" technology list, realize the "two-type, low-carbon" development of highway maintenance projects, and create a new situation of scientific and coordinated sustainable development.

\section{Application of Green Innovation Technology}

The adoption of innovative technologies can improve the content of engineering science and technology and optimize the economic indicators of engineering technology, which is an important channel to achieve the optimal economic, social and environmental benefits. Therefore, "four new" technologies are increasingly valued and applied by relevant departments[3,4]. The Yunmao Expressway combines the technical requirements and management requirements of the project construction, vigorously promotes the integrated application of the "four new" scientific and technological achievements, and closely focuses on the assembly, ecological, safe, intelligent, and innovative "one transformation and four transformations", focusing on Assembled design and construction, resource-intensive and economical utilization technology, energy saving and consumption reduction, green energy development and utilization technology, low-pollution construction technology, safe construction, safe operation, construction wisdom management and control, etc. Thematic demonstrations were conducted, and 52 green highway demonstration technologies were integrated and applied to build a pilot demonstration project of green highway construction in the western Guangdong region of Guangdong Province, and strive to cast the Yunmao Expressway into a "Guangdong model" for green highways and quality projects.

\subsection{Construction safety and intelligent management and control}

\subsubsection{Integrated monitoring and monitoring technology for dust, noise and video}

The integrated monitoring system of dust, noise and video is used for on-line monitoring of real-time data on the construction sites of Yunmao Expressway, etc., where the monitored data includes dust concentration, noise index and video images. Through the Internet of Things and cloud computing technology, real-time, remote, and automatic monitoring of particulate matter concentration and on-site data transmission through the network are achieved. When the dust monitoring system is working, it will automatically collect some data that exceeds the standard value, and then transfer the collected data to the server through the network. It also has an automatic alarm function, which can control the changes in the environment at any time, and then inform the relevant parts for rectification. It also has alarm linkage information output, and can be connected to external spray dust reduction equipment to achieve linkage.

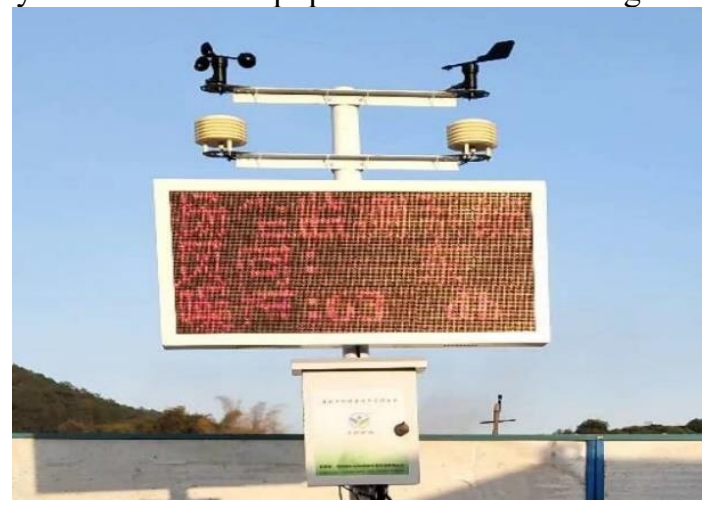

Figure 1. Application case of integrated monitoring of dust, noise and video

\subsubsection{Construction safety risk monitoring and control technology}

Yunmao Expressway is a typical mountain expressway, with many construction difficulties and high construction intensity. In order to achieve real-time monitoring of construction safety, the project monitors the entire line in real time, and comprehensively, timely and accurately understands the monitoring data through the cloud platform system. Timely grasp the early warning information of dangerous sources of the monitoring body. When the danger source is early warning, the early warning information can be received through the mobile phone; the body's danger source dynamics can be controlled at any time. 


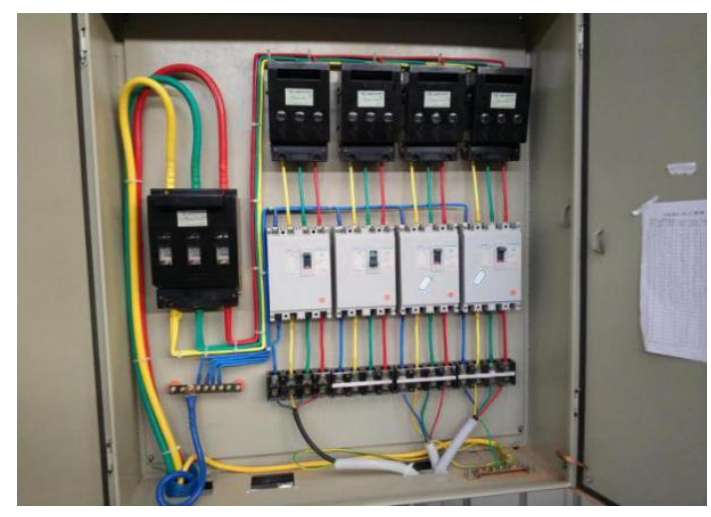

Figure 2. Standard distribution box

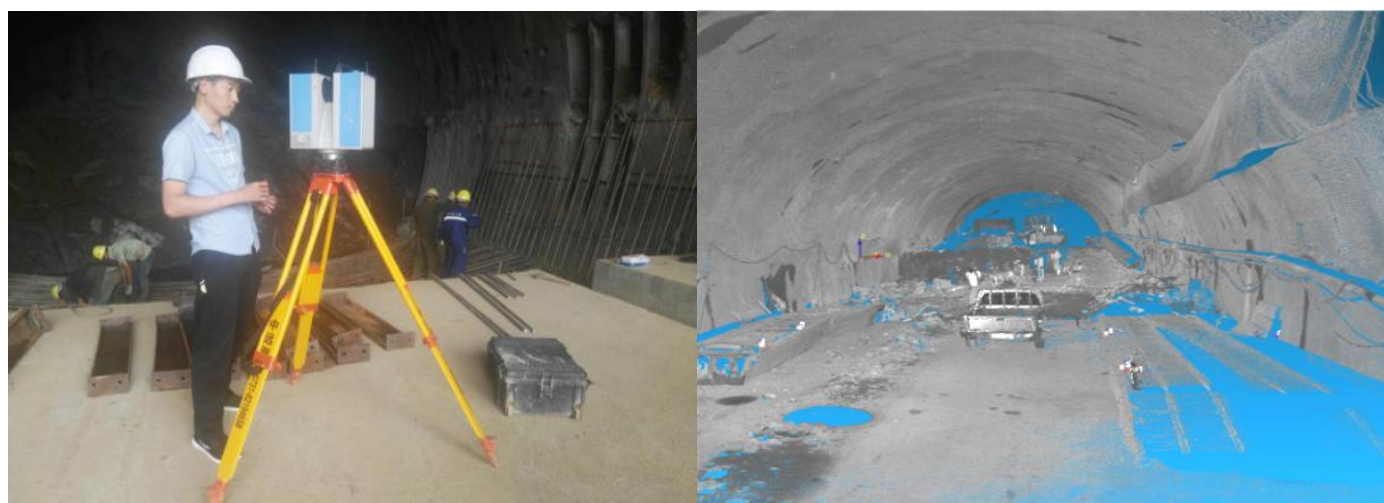

Figure 4. On-site monitoring

\subsubsection{GNSS-based automatic monitoring system for high slope deformation}

The project selects 9 high-grade 4 or higher slopes across the line for automatic four-dimensional monitoring of surface displacement and deep deformation. The cloud platform system comprehensively, timely and accurately understands the status of various monitoring data, and timely grasps the early warning information of dangerous sources of the monitoring body. When the danger source is early warning, the early warning information can be received through the mobile phone; the body's danger source dynamics can be controlled at any time. The relevant real-time data and images of the landslide body can be dynamically viewed through the network; the operation status of the monitoring body can be grasped at any time.

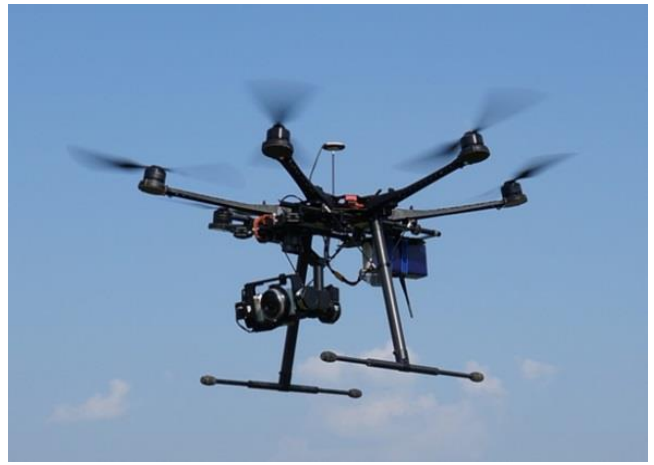

Figure 6. Automatic surface displacement monitoring equipment

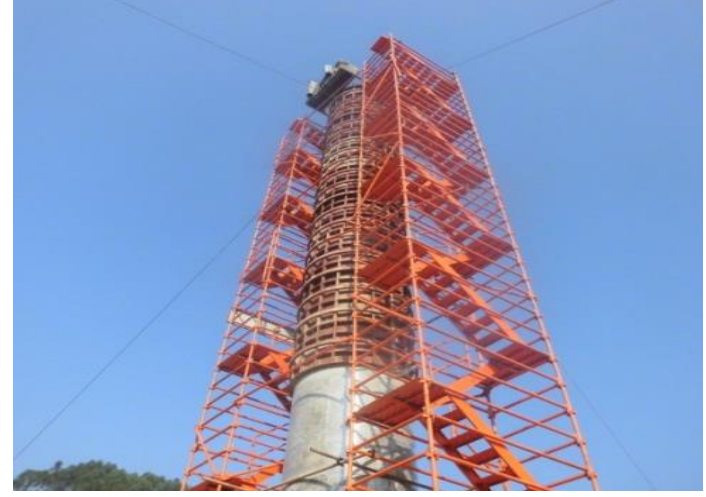

Figure 3. Shaped safety ladde

Figure 5. Monitoring cloud map

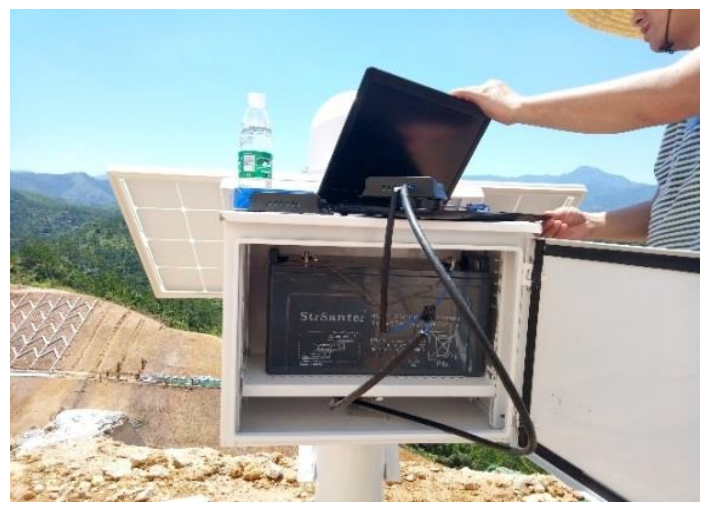

Figure 7. Automatic monitoring system for high slope deformation

Through these improved technologies, labor intensity and labor input are reduced, the quality and efficiency of construction management of the project is improved, rework and waste of resources are reduced, and the construction period is guaranteed.

\subsection{Green and low-carbon construction process}

\subsubsection{Complete set of tunnel lining construction technology}

Aiming at the problems of current tunnel construction, the surface of the secondary lining concrete forms a herringbone flow line or aggregate accumulation, the lining needs to be grouted several times, and the subsequent grouting cannot form an integral structure 
with the lining concrete[5]. In order to ensure the tunnel, the lining construction quality guarantees the safety of later operations. Yunmao Expressway actively explores the complete set of lining technology for using two-lined concrete chute to enter the mold window by window and vaulted tunnel lining grouting. In 2017, Yunmao Expressway wrote this process into the construction contract, and this process is applied to the construction of the two-line concrete for the entire tunnel. Yunmao Expressway is the first expressway project in China to fully use this technology. The appearance quality of the second lining has been greatly improved, and the vulnerabilities of the vaults are almost extinct(Third-party testing units have carried out the emptying test according to the testing methods of the provincial quality supervision station, and no vulcanization of the second lining vaults or concrete is not found).

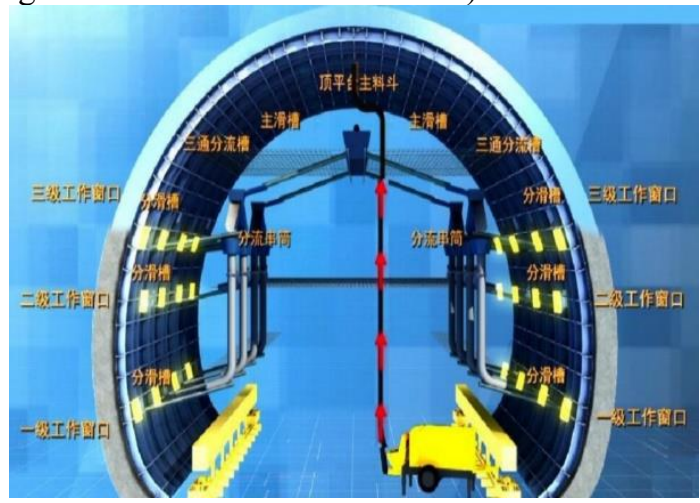

Figure 8. Schematic diagram of layer-by-window pouring cart

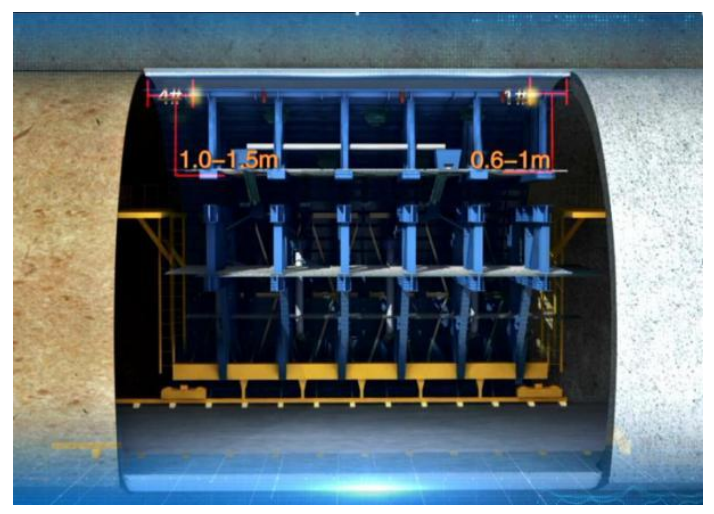

Figure 9. schematic diagram of grouting hole layout with mold

\subsubsection{Blasting with concentrated water pressure and smooth surface}

During the construction of Yunmao Expressway, there are a large number of tunnels, and the safety and environmental protection issues during the tunnel construction period are prominent. It is necessary to vigorously promote the low-carbon environmental protection tunnel construction technology. The traditional manual drilling and blasting method has low construction efficiency, blasting quality is not easy to control, serious dust pollution in the cave, and workers have suffered greater occupational health hazards[6]. Starting from the goal of building a "green, high-quality, safe, and smart" highway, Yunmao Expressway adopted a concentrated energy hydraulic blasting technology in the highway tunnel excavation operation. "Explosive-charged energy tube" and water bag (Fig 9) are used in the gun hole, and the gun mouth is used for filling. The excavation contour line is smooth and smooth, and there is no "langya jag" phenomenon, which reduces the stress concentration on the surrounding area. The hazard of rock stability reduces the construction safety risk, and at the same time, the overexcavation is effectively controlled, which brings quality assurance for the subsequent wet spraying, waterproof board installation and second lining construction; the number of holes in the surrounding eye is reduced by half, which shortens the drilling Time, to improve the efficiency; water mist to reduce dust, reduce dust pollution to the environment, at the same time reduce ventilation time, reduce energy consumption, and improve economic efficiency. In general, the effect of "three enhancements and one protection" has been achieved, that is, "improving the energy utilization rate of explosives, improving the tunneling efficiency, improving economic benefits, reducing dust and improving the operating environment." 

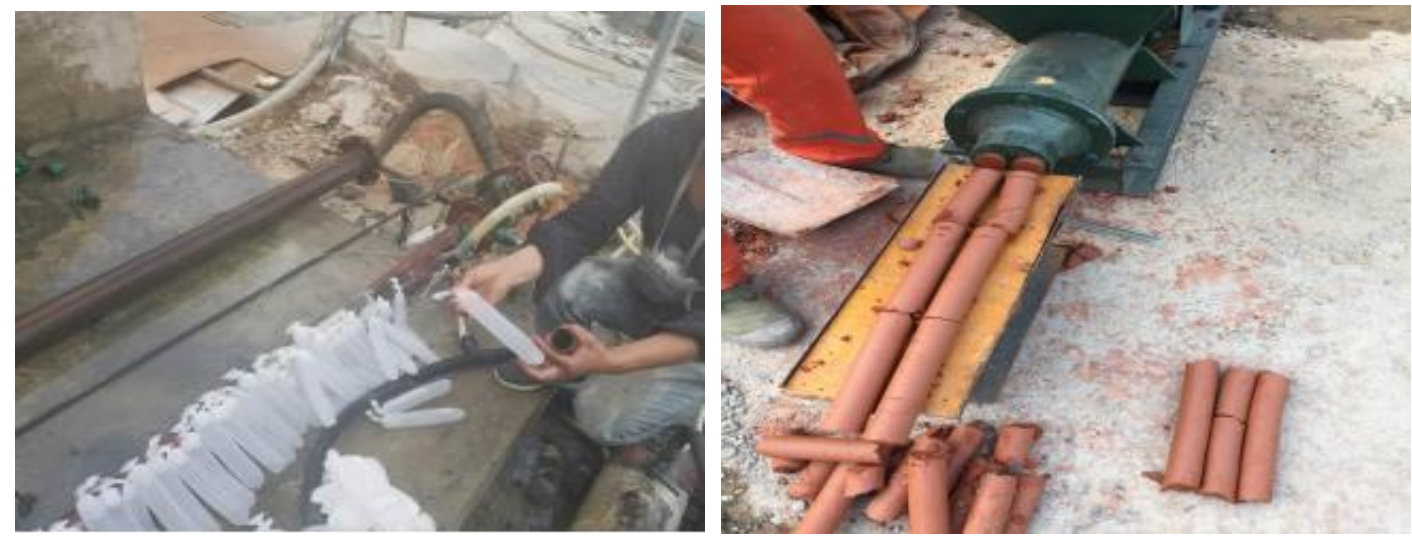

Figure 10. Water bag processing and gun mud production

\subsubsection{Alkali-free accelerator and wet spraying process}

During the excavation of the Jinlin Tunnel and the Huanglou Tunnel, the Yunmao Expressway adopted an alkali-free quick-setting agent and a wet spray process, and invested 3 large wet spray machines with a spray volume of about $32,000 \mathrm{~m} 3$. Traditional alkaline accelerators contain alkaline ions, which can not guarantee the construction environment during the sprayed concrete process, which will harm the skin of the construction workers. The concrete has low compactness, slow strength development in the early stage, and is easy to produce alkaline aggregate reaction. High bounce, high waste, small thickness in one shot. In contrast, alkali-free quick-setting agents have the following advantages: (1) increase the compactness of concrete; (2) reduce the occurrence of alkali aggregate reaction; (3) eliminate physical injuries to construction workers; (4) can improve the durability of sprayed concrete[7].

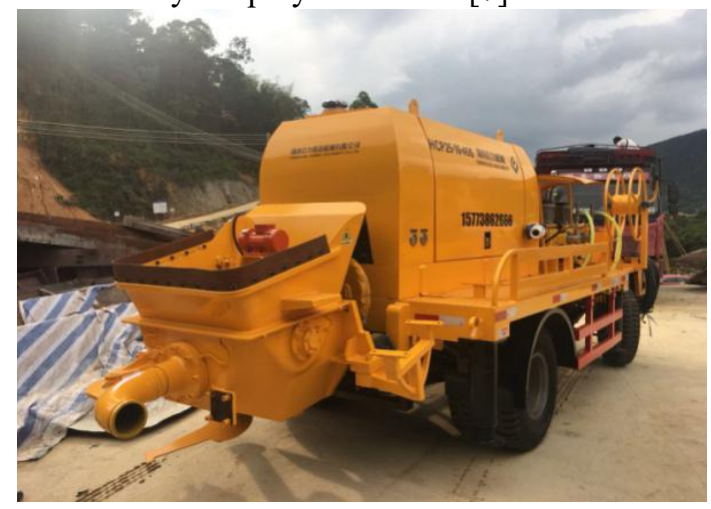

Table 1 shows the performance comparison between wet shotcrete construction and dry shotcrete construction.

Table 1. Comparison of construction performance of dry and wet sprayed concrete

\begin{tabular}{|c|c|c|}
\hline Spray process & Dry spray process & $\begin{array}{l}\text { Wet spraying } \\
\text { process }\end{array}$ \\
\hline $\begin{array}{l}\text { Water-cement } \\
\text { ratio }\end{array}$ & $\begin{array}{l}\text { Water-cement ratio } \\
\text { is difficult to } \\
\text { control }\end{array}$ & $\begin{array}{c}\text { Water-cement ratio } \\
\text { can be accurately } \\
\text { controlled }\end{array}$ \\
\hline Compactness & $\begin{array}{l}\text { Poor compactness } \\
\text { and low concrete } \\
\text { strength grade }\end{array}$ & $\begin{array}{l}\text { Good compactness } \\
\text { and high concrete } \\
\text { strength grade }\end{array}$ \\
\hline Accelerator & $\begin{array}{l}\text { Rough accelerator } \\
\text { control }\end{array}$ & $\begin{array}{l}\text { Accurate } \\
\text { accelerator control }\end{array}$ \\
\hline Rebound rate & High rebound rate & Low rebound rate \\
\hline Dust amount & $\begin{array}{l}\text { Higher dust } \\
\text { concentration }\end{array}$ & $\begin{array}{c}\text { Low dust } \\
\text { concentration }\end{array}$ \\
\hline $\begin{array}{c}\text { Capital } \\
\text { investment }\end{array}$ & $\begin{array}{l}\text { Simple equipment } \\
\text { and small } \\
\text { investment }\end{array}$ & $\begin{array}{c}\text { Complex } \\
\text { equipment and } \\
\text { large investment }\end{array}$ \\
\hline
\end{tabular}

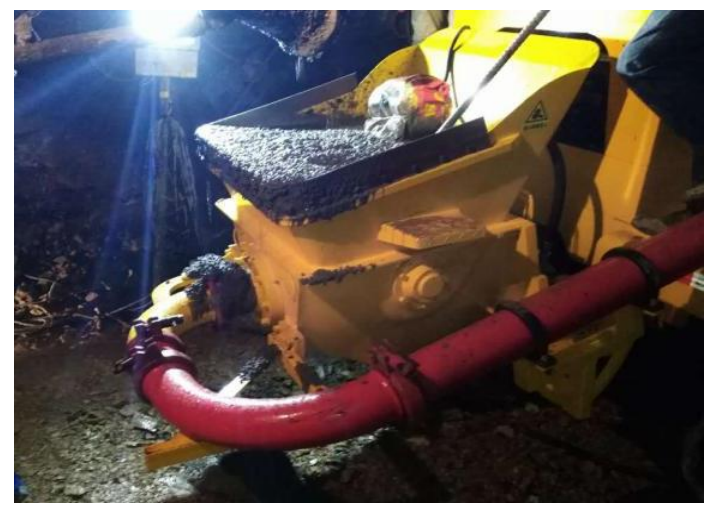

Figure 11. Tunnel wet sprayer

\subsubsection{Carbon dioxide protective welding process}

Carbon steel protective welding technology is used in the rebar processing plant, prefabrication plant and tunnel steel structure processing plant along the Yunmao Expressway. The traditional method uses arc welding, which has large energy consumption, high consumables, low efficiency, poor working environment and low automation. There are many arc welding points, which are easy to cause penetration and cracks. Arc welding produces more slag. $\mathrm{CO}_{2}$ gas shielded welding technology is of high quality, high efficiency, energy saving, low power consumption, low emissions, and environmentally friendly. $\mathrm{CO}_{2}$ gas shielded welding has strong penetration ability, large welding current density $\left(100-300 \mathrm{~A} / \mathrm{m}^{2}\right)$, small deformation and high production efficiency. $\mathrm{CO}_{2}$ gas shielded welds have strong rust resistance, low hydrogen content, and low tendency for cold cracking. 
$\mathrm{CO}_{2}$ gas shielded welding has no welding slag, beautiful

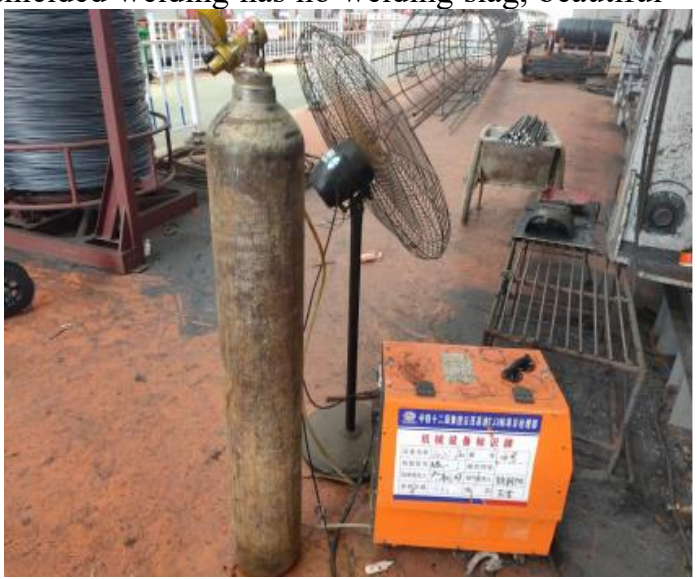

welding seam and high quality.

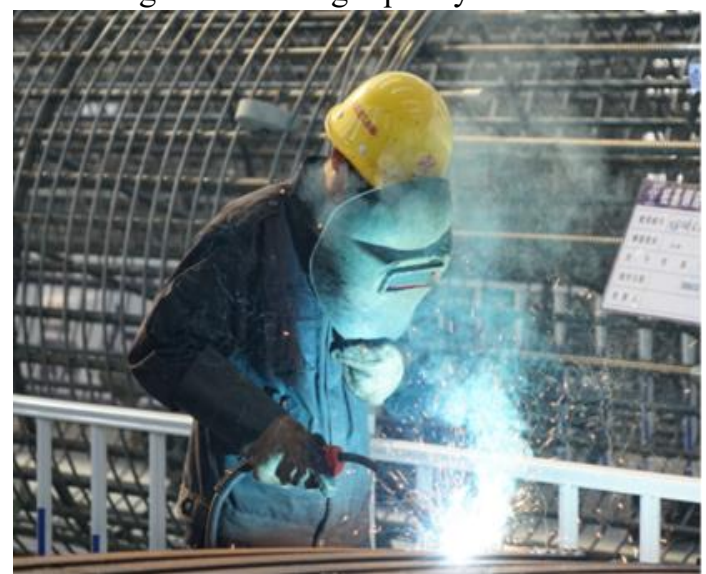

Figure 12. Rebar processing plant, prefabricated plant, tunnel steel structure using carbon dioxide protection welding

\subsection{New green energy-saving equipment}

\subsubsection{Fiber Anchor}

Fiber anchors were used in the TJ9 section (Fig 13). The corrosion resistance and durability of traditional metal anchors are poor, which greatly affects the application range and engineering life of geotechnical anchoring technology, especially in special strata and permanent

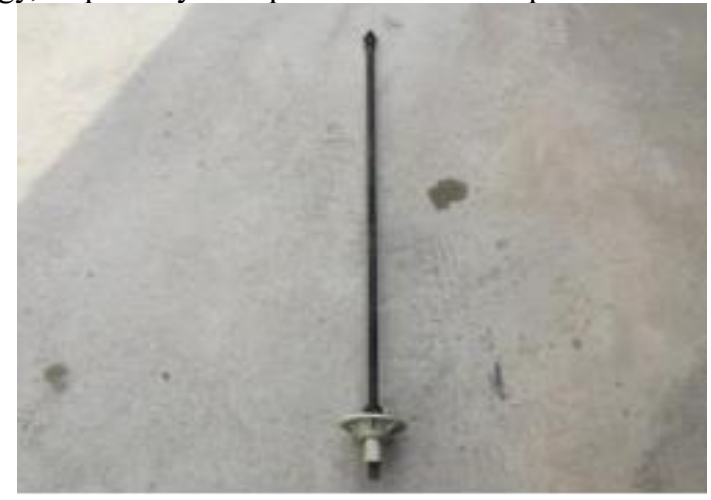

geotechnical layers where Yunmao Expressway is located. The application has been greatly restricted. Fiber anchor is a composite fiber rod body made by pultrusion. It uses synthetic resin as a binder and composite fiber as a reinforcing material. It has high tensile strength, strong corrosion resistance, light weight, and fast anchoring response. Easy to process. The left and right tunnels of the Jinlin Tunnel each have $100 \mathrm{~m}$ level IV surrounding rock sections, using about 4,100 sets, totaling $15,400 \mathrm{~m}$.

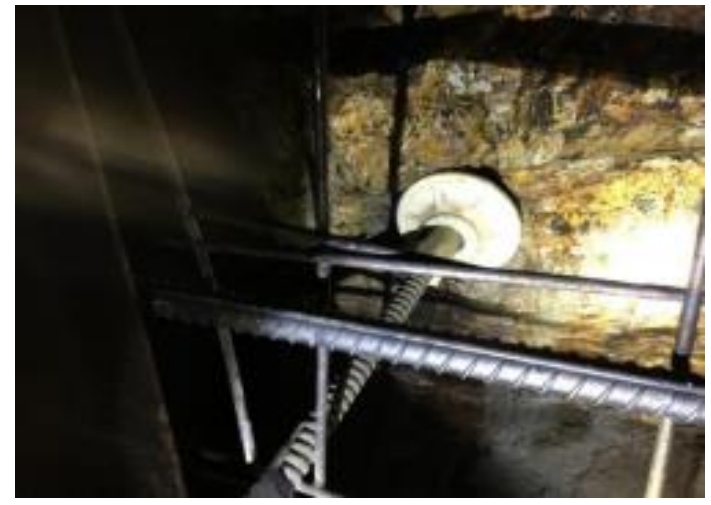

Figure 13. Fiber anchor

\subsubsection{Fog Cannon}

In the TJ9 standard Jinlin Tunnel and Huanglou Tunnel, there are 8 fog guns for tunnel dust removal and health maintenance (Fig 14). The traditional methods of tunnel dust removal include the manual hand-held spray gun method and the sprinkler spray method. These methods have problems such as large water consumption, low dust removal efficiency, and long dust removal time. The fog cannon machine uses the imported high-pressure pump and fine atomizing nozzle to atomize the water according to the principle of air delivery, and then uses the fan's air volume and wind pressure to transport the atomized water mist to a longer distance, so that the water mist reaches the longer distance. At the same time, it can cover a larger area, and the water mist and dust condense and land, so as to achieve the purpose of dust reduction. Fog gun dust removal has the following characteristics: $\Phi$ long range, wide coverage, high work efficiency, can achieve precise spraying; 2 the sprayed mist particles are small, and when it comes into contact with dust, it forms a wet mist, which can Quickly suppress the dust; 3 The supporting power is flexible, and it can be powered by three-phase $380 \mathrm{~V}$ city power or diesel generator sets; $\&$ It can be fixedly installed on the concrete pouring platform, or it can be installed on the transportation vehicle with diesel generator; 5 flexible operation, remote or manual control, and can adjust the horizontal rotation and spray angle at will, safe and reliable use; 6 water consumption can save $70 \%-80 \%$ compared with other dust suppression spraying equipment (spray gun, sprinkler) $\%$, And the area covered by water mist is much larger than other dust suppression spraying equipment; $\bar{\phi}$ range 60 meters-200 meters optional, can be configured according to the actual requirements of customers. 

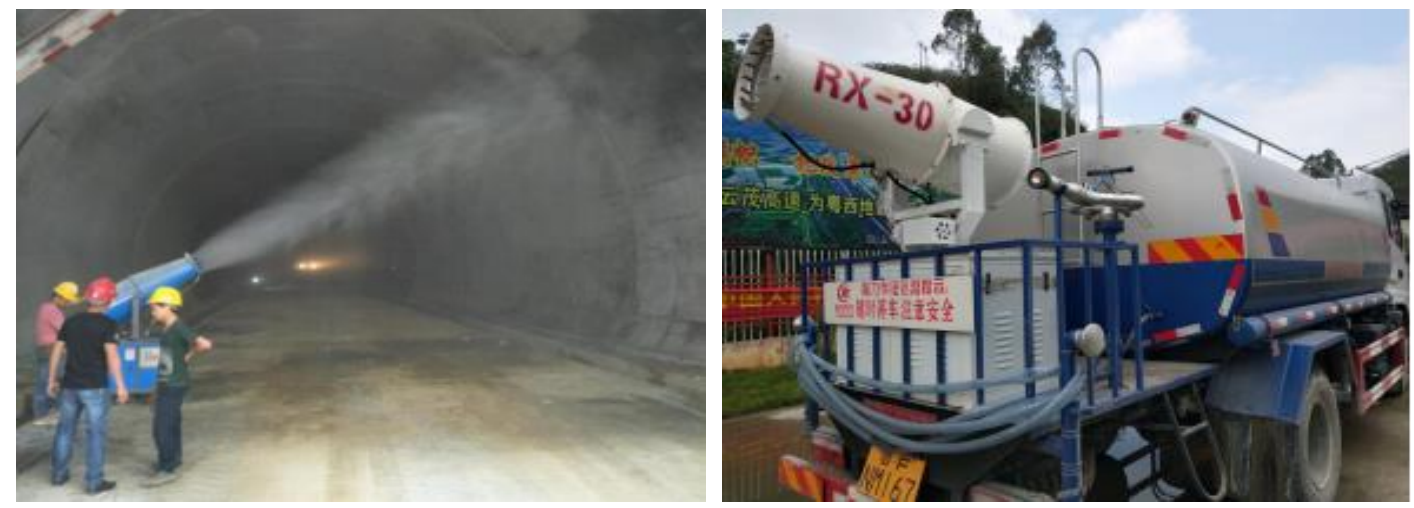

Figure 14. dust removal and health maintenance of fog gun

\subsubsection{Automatic Welding Machine for Tunnel Steel Mesh}

Yunmao high-speed construction is equipped with an automatic welding machine for the reinforcement mesh of the tunnel (Fig 15). Traditional welding machines generally suffer from shortcomings such as large gap errors in the reinforcement, weak welding, burnt reinforcement, low efficiency, and high energy consumption. The quality of the reinforcement mesh is also very high. Difficult to control. The automatic welding

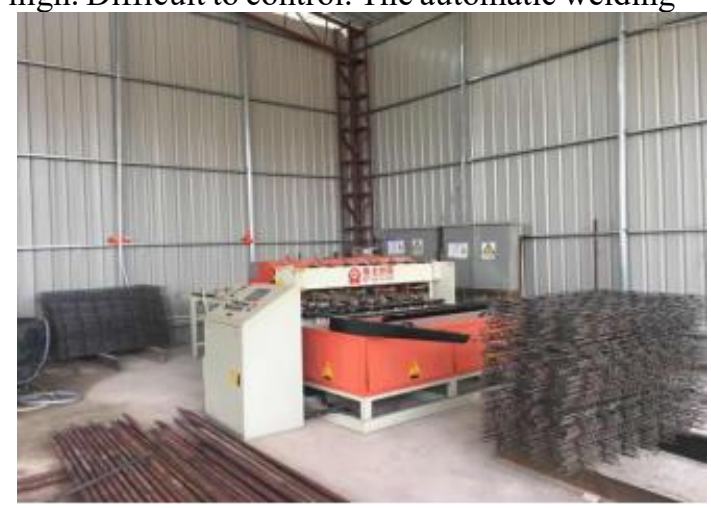

machine for tunnel steel mesh is used to make the edges of the welding mesh neat, the grid spacing error is controlled at $\pm 2 \mathrm{~mm}$, and the welding is firm and without burns. This automatic welding welding process not only has high construction quality, high construction efficiency, and low operation intensity. Just one person can do it. It can produce $1.5 \mathrm{~m} \times 2.0 \mathrm{~m}$ per hour, $60-80$ pieces of reinforced mesh with a grid spacing of $20 \mathrm{~cm} \times 20 \mathrm{~cm}$, which is more than twice the efficiency of the traditional process. Automatic mesh welding machine equipment is cheap, small footprint, light weight, easy to install and remove.

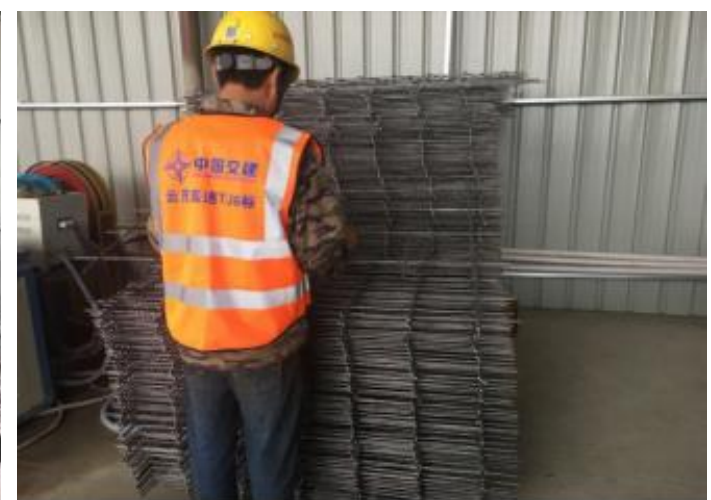

Figure 15. Automatic Welding Machine for Tunnel Steel Mesh

\subsubsection{CNC bending machine}

Yunmao Express uses standard CNC bending center technology for all standards. The traditional method is to add tools to the manual bending machine, which will

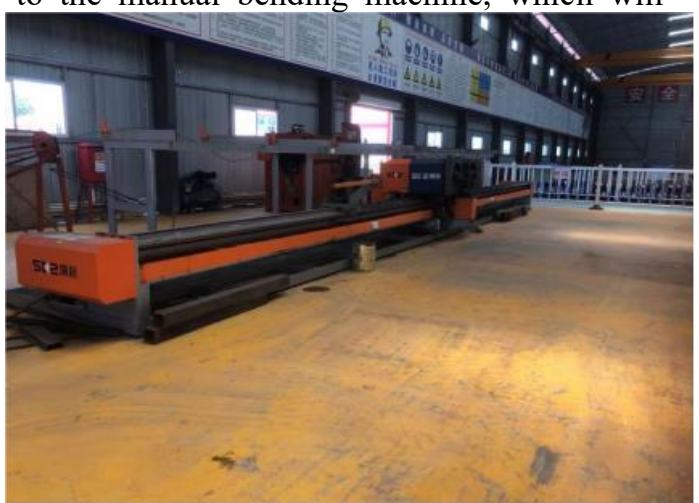

inevitably have disadvantages such as low accuracy and low work efficiency. The use of CNC bending machines will greatly improve the precision of steel bar production and increase work efficiency. Especially for rebars with more complex dimensions and more bending points, the work efficiency is greatly improved (Fig 16).

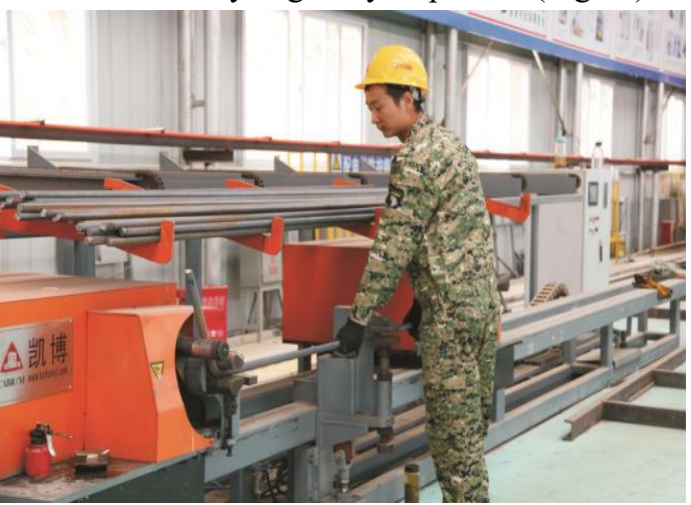

Figure 16. CNC bending of steel bars 


\section{Prospects for Green Highway Innovation Technology}

Yunmao Expressway will "fully implement the new concept, technology and system of green highway construction, and by 2020 , it will cover all key highway construction projects in the province, forming a unique Guangdong green highway technology system, standard system and brand" As the goal, with the concept of "green highway", various emerging technologies will also be continuously applied to the project construction process. As a highway builder, we must actively learn and promote various technological innovations, carry forward the "craftsman spirit", and build high-quality highways.

\section{Conclusion}

From the current development status of highway construction, it can be seen that green innovative technology can significantly improve the design level and construction quality of highway engineering, and at the same time can effectively reduce the problems and common problems that will be faced during the later construction and maintenance of highway engineering. Therefore, only from the start of the construction party to pay attention to technological innovation, to the design side to study it, the supervision side to supervise, and finally to the implementation side by item by the construction side, can it be gradually applied and developed in the highway construction process. The goal of creating a "quality project" is to provide guarantee.

\section{References}

1. Fu X. (2017) Current Situation and Discussion on the Application of the Four New Technologies of the Provincial Highway in Jiaxing City. In: The Conservation and Management Branch of the China Highway Society. Xian. 5.

2. Dou J. (2004) On the Application of "Four New" Technology in Highway Engineering. Anhui Architecture, (05): 79-80.

3. Ji X H. (2018) Application of "Four New" Technology in Highway Maintenance. Maintenance and Management, No. 2 (Total Issue 84).

4. Rao K X. (2018) Application of "Four New Technologies" in Highway Engineering. New Technology \& New Products of China, (1): 108-109.

5. Zhao X Z. (2015) Talking about the construction method of the second lining of the tunnel. Heilongjiang Communications Science and Technology, (04): 154-156.

6. Liu H B. (2019) Application of the new technology of concentrated energy hydraulic pressure smooth blasting in the construction of Chenglan railway tunnel. Modern Tunnel Technology, 56 (02): 188-193.

7. Cui X M. (2015) Application of non-alkali wet sprayed concrete in tunnel construction. Value 